\title{
COPY OF:
}

Rayner, K., White, S.J., Kambe, G., Miller, B., \& Liversedge, S.P. (2003). On the processing of meaning from parafoveal vision during eye fixations in reading. In J. Hyönä, R. Radach, \& H. Deubel (Eds). The Mind's Eye: Cognitive and Applied Aspects of Eye Movement Research (pp. 213-234). Amsterdam: Elsevier.

\section{NOT THE FINAL PUBLISHED VERSION}


On the processing of meaning from parafoveal vision during eye fixations in reading

\author{
Keith Rayner \\ University of Massachusetts, Amherst \\ Sarah J. White \\ University of Durham \\ Gretchen Kambe \\ University of Nevada, Las Vegas \\ Brett Miller \\ University of Massachusetts, Amherst \\ and \\ Simon P. Liversedge \\ University of Durham
}

Running Head: Parafoveal processing during reading

Correspondance to:

Keith Rayner

Department of Psychology

University of Massachusetts

Amherst, MA 01003

rayner@psych.umass.edu 


\begin{abstract}
Research dealing with parafoveal processing during eye fixations is reviewed. Four main topics are addressed: (1) parafoveal processing, (2) word skipping, (3) preview benefit effects, and (4) parafoveal-on-foveal effects. We argue that word skipping effects reflect the fact that a parafoveal word (word $n+1$ ) has been identified on the fixation on word $n$. We also review evidence which strongly suggests that preview benefits during reading are not due to semantic processing of a parafoveal word. Finally, we review the more recent and more controversial research suggesting that the meaning of word $n+1$ can influence the fixation time on word n, and argue that it is premature at this point to accept the validity of such findings with respect to normal reading. Implications of the research for serial attention shift models like the E-Z Reader model are also discussed.
\end{abstract}


While a great deal has been learned about eye movements during reading over the past twenty-five to thirty years (Liversedge \& Findlay, 2000; Rayner, 1978, 1998), there remain a number of unresolved issues (Starr \& Rayner, 2001). In this chapter, we will focus our discussion on research related to one of these unresolved issues: parafoveal semantic processing of words. Research on this issue has apparently gained momentum because it has been assumed that if there were so-called parafoveal-on-foveal effects, or evidence that the meaning of the word to the right of fixation influences the duration of the fixation on the currently fixated word, it would be damaging to serial attention shift models such as the E-Z Reader model (Reichle, Pollatsek, Fisher, \& Rayner, 1998). We will return to this issue at the end of the chapter. However, before discussing the relevance of such research for the E-Z Reader model, we will first provide a general review of research on parafoveal processing and then discuss in turn (1) word skipping, (2) preview benefit effects, and (3) parafoveal-onfoveal effects.

We argue that readers can identify word $n+1$ while fixating word $n$. When they do, its meaning becomes available and can influence fixation times on word $\mathrm{n}$ (and also word $\mathrm{n}+2$ ). Furthermore, if word $\mathrm{n}+1$ is identified, then the reader will skip that word. However, the primary argument we will make in this chapter is that if word $n+1$ is not identified then its meaning does not become available and therefore cannot affect fixation time on word $\mathrm{n}$. In such a situation, word $n+1$ will typically not be skipped but must be fixated in order for word identification to occur. We argue that it would be premature at this point to accept evidence from studies that claim to show parafoveal-on-foveal effects as being very strong. Some of the evidence is based on tasks that may or may not easily generalize to reading and some of the evidence is inconsistent: while there are some studies showing parafoveal-on-foveal effects, there are also a number of studies that do not show such effects. While we will argue against the validity of some claims regarding parafoveal-on-foveal effects, we also 
readily agree that the case of word skipping according to our theoretical biases is prima facie evidence that the meaning of non-fixated words can be processed. Importantly, although word skipping shows that the meaning of parafoveal words can be processed, the characteristics of such words do not necessarily directly modulate the duration of the current fixation (parafoveal-on-foveal processing). To restate our general claim, we will argue that if a word is skipped, the meaning of that word was accessed on the current fixation (when the word in question was to the right of the currently fixated word). But, we will also argue that in the more frequent case when the word to the right of fixation is not skipped on the ensuing saccade that there is no solid support from the research data in reading tasks for (1) semantic preprocessing resulting in semantic preview benefits or (2) semantic preprocessing influencing the duration of the current fixation, that is parafoveal-on-foveal effects. This is not to say that such effects do not occur. Rather, our argument is that the evidence supporting such effects is questionable at this point in time.

Finally, before we turn to our review of parafoveal processing, we note that we are not arguing that no information is obtained from parafoveal words during reading. Indeed, in our review of preview benefit effects we will document that there are robust effects due to having a preview of a word before fixating on it. Furthermore, there is evidence for parafoveal-on-foveal effects due to unusual orthography at the beginning of the word to the right of fixation. Again, what we will be questioning is the extent to which the parafovealon-foveal effects are typical of normal reading.

\section{Parafoveal Processing During Reading}

It is clearly the case that foveal processing is critically important in reading. Indeed, it is generally agreed that the main purpose of eye movements during reading is to bring a region of text into foveal vision (the 2 degrees of central vision where acuity is highest) for 
detailed processing (Rayner, 1998). Readers need to get a good foveal glimpse of most of the words in the text for reading to proceed smoothly. On the other hand, reading on the basis of extra-foveal or parafoveal information is quite difficult, if not next to impossible (Rayner \& Bertera, 1979; Rayner, Inhoff, Morrison, Slowiaczek, \& Bertera, 1981). Parafoveal vision is typically assumed to correspond to that part of the visual field falling from the end of the fovea out to about five degrees to the right of the fixation point, and likewise out to five degrees to the left of fixation. However, since information to the right of fixation is more important than information to the left for readers of English (Rayner, Well, \& Pollatsek, 1980), we will focus our discussion on parafoveal information to the right of fixation.

Although we have defined parafoveal vision in terms of degrees of visual angle, it is well known in reading that number of letters is the more appropriate metric to use than visual angle. This is because when the same text is read at different distances, even though the letters subtend different visual angles, the number of letters traversed by saccades is relatively invariant (Morrison \& Rayner, 1981; O’Regan, 1983; O’Regan, Lévy-Schoen, \& Jacobs, 1983). Since for most normal sized text 3 or 4 letters equals one degree of visual angle, letters in parafoveal vision would typically extend from the $4^{\text {th }}$ or $5^{\text {th }}$ letter to the right of fixation out to the $15^{\text {th }}$ or $20^{\text {th }}$ letter to the right of fixation. Because acuity drops off steadily from the center of fixation, words presented in parafoveal vision are harder to accurately identify, and they take longer to identify, than words presented in foveal vision. Indeed, if a word of normal sized print is presented in parafoveal vision, it is identified more quickly and accurately when a saccade is made than when a saccade is not made (Jacobs, 1987; Rayner \& Morrison, 1981). Thus, even though the program for planning and executing a saccade takes about 175-200 ms on average (Rayner, Slowiaczek, Clifton, \& Bertera, 1983), it is functional to move the eyes rather than hold them still.

The importance of parafoveal vision in reading was clearly demonstrated in the 
classic moving window studies (McConkie \& Rayner, 1975; Rayner \& Bertera, 1979). In these experiments, the eye-contingent display change technique was first introduced; readers' eye movements were monitored, and the amount of information that was available for processing on each fixation was controlled through the use of a moving window procedure (in which the appropriate text was available within the window and all letters outside of the window were perturbed in some way). These experiments, and many subsequent experiments (see Rayner, 1998 for an overview), demonstrated that when readers have the appropriate text information out to14-15 letter spaces to the right of fixation (and information to the beginning of the currently fixated word or 3-4 letters to the left of fixation) that reading proceeds as if there was no window (i.e., the text was normal). So, clearly parafoveal information is being used in reading. Other experiments (see Rayner, Well, Pollatsek, \& Bertera, 1982) using the moving window paradigm demonstrated that if only the fixated word was available for processing within the window that reading rate was considerably slower than when more information was available. On the other hand, the reading rate was only about 20 words per minute slower than the full line condition when either readers had the currently fixated word and the word to the right of fixation available, or if they had the currently fixated word available as well as the first 3 letters of the next word (with the other letters replaced by visually similar letters). So, having only a single word slows reading, but having the fixated word and either the next word or the beginning letters of the next word (and the rest of the letters replaced with visually similar letters) available is almost as good as having the whole line. These results clearly demonstrate that both foveal and parafoveal information are important in reading.

The other thing that the original McConkie and Rayner (1975) study made apparent (also confirmed by a great deal of subsequent research, see Rayner, 1998) is that word length information (marked by the spaces between words) is critically important for programming 
saccades. Readers use the space information in parafoveal vision to program where their next saccade will go. It is also clear that some words in parafoveal vision can be identified without a direct fixation. Certainly, short words falling just to the right of fixation can be identified without direct fixation (Rayner, 1979; Rayner \& McConkie, 1976). This leads us to the issue of word skipping, which we discuss in detail in the next section. Before moving to that topic, however, let us discuss the issue of parafoveal semantic preprocessing.

The idea of parafoveal semantic preprocessing was introduced by Underwood (1985) and referred to the notion that semantic processing of words to the right of fixation in the parafovea led to (1) faster recognition of that word on the next fixation (when the parafoveal word was directly fixated) and (2) rather intelligent guidance of the eyes to informative regions in text. We shall delay discussion of the first component of semantic preprocessing until the section on Preview Benefit. In the remainder of this section, we will briefly discuss the issue of eye guidance based on semantic preprocessing.

In a series of interesting experiments, Underwood and colleagues (Underwood, Bloomfield, \& Clews, 1988; Underwood, Clews, \& Everatt, 1990; Underwood, Clews, \& Wilkinson, 1989; Everatt \& Underwood, 1992; Hyönä, Niemi, \& Underwood, 1989) examined the eyes' landing position in long words (10 or more letters) composed of informative and redundant halves. They reported that the eyes tend to initially move further into a word when the informative information is at the end of the word than at the beginning and suggested that semantic preprocessing of parafoveal words was responsible for the effect. However, the effect was sometimes small and sometimes non-significant. More importantly, in carefully controlled experiments, neither Rayner and Morris (1992) nor Hyönä (1995; see also Radach, Krummenacher, Heller, \& Hofmeister, 1995) were able to replicate this effect. They did demonstrate that readers quickly moved out of the beginning of a word when it was redundant (so that they could get to the more informative part of the word), but there was no 
evidence that the eyes initially moved further into words when the informative information was at the end of the word. In short, the data purporting to show semantic preprocessing in the parafovea do not provide compelling evidence to support the idea because of these failures to replicate the effect.

It is clearly the case that low level word length information acquired from parafoveal vision during reading is used in guiding eye movements to the next fixation location (Pollatsek \& Rayner, 1982; Rayner, Fischer, \& Pollatsek, 1998). Furthermore, as shall be seen in the section on preview benefits, partial word information is obtained and used on the subsequent fixation to facilitate word recognition. But, our view is that readers typically don't acquire information regarding the meaning of parafoveal words. The obvious exception to this general statement is with respect to word skipping, to which we now turn.

\section{Word Skipping During Reading}

Whereas most of the words in a text are fixated, it is still the case that up to one third of the words are skipped. The most obvious case when words are skipped is when they are short (Blanchard, Pollatsek, \& Rayner, 1989; Brysbaert \& Vitu, 1988; Rayner \& McConkie, 1976; Rayner, Sereno, \& Raney, 1996). Since short words (under 3 letters long) are very frequent in English text, a lot of words are skipped simply because they are short. Whereas words that are 7-8 letters long are fixated most of the time in English, words that are under 3 letters long are skipped far more often than they are fixated. When two or three short words occur in succession in text, together they will typically only receive a single fixation. So, these words are apparently all identified on the same fixation. Likewise, when the word falling just to the right of the currently fixated word is short, it is typically also skipped and apparently identified on the fixation prior to the skip. However, it can't be the case that word length is the only factor that influences skipping. For example, O’Regan $(1979,1980)$ found that the function word the was skipped more frequently than 3-letter content words (see 
Gautier, O’Regan, \& LaGargasson, 2000 for more recent confirmation of this finding), presumably because it is more predictable, more visually familiar, and/or more frequent than the content words. Furthermore, Kennison and Gordon (1998) found differential skipping rates for different types of pronouns (of the same length), so perhaps the function that the pronoun serves is a factor. Thus, while it is clearly the case that word length exerts a very strong influence on skipping, it is also clear that other factors besides word length play a role.

Contextual constraint (or how predictable a word is from the prior context) also influences skipping behavior. This effect was first demonstrated by Ehrlich and Rayner (1981) who found that highly constrained words were skipped more frequently than unpredictable words. In subsequent work, Rayner and Well (1996) examined a range of predictability constraints so that target words were highly predictable (meaning that subjects could identify the target word in a cloze task $86 \%$ of the time), medium predictable ( $41 \%$ cloze accuracy), or low predictable (4\% cloze accuracy). Table 1 shows example sentences and the basic results from the Rayner and Well study.

\section{Insert Table 1 about here}

If we first consider the fixation time measures, we see that in first fixation duration (the duration of the first fixation on the target word independent of the number of fixations that were made) and gaze duration (the sum of all fixations on the target word before moving to another word), the high and medium predictability conditions were almost identical and both yielded shorter fixation times than the low predictability condition. However, when we consider the probability of fixating on the target word, we see that the medium and low predictability conditions did not differ from each other, and both were more likely to yield a fixation on the target word than the high predictable condition. Combined with results reported by Hyönä (1993), it is clear that only highly predictable words are skipped during reading (when the target words are not short). 
Our view is that if a word is skipped, it was processed on the prior fixation. Pollatsek, Rayner, and Balota (1986) reported that when a word is skipped, the duration of the prior fixation is inflated. Furthermore, there is some evidence suggesting that the duration of the fixation following a skip is also inflated (Reichle et al., 1998). These results are a bit controversial at the moment since two analyses based on large corpora of data (Engbert, Longtin, \& Kliegl, 2002; Radach \& Heller, 2000) did not yield strong evidence of inflated fixations prior to a skip. However, in a recent analysis, Rayner, Ashby, Pollatsek, and Reichle (2002) again found an effect in which the duration of a fixation prior to skipping a predictable word was inflated by 23 ms. Longer fixation durations before skipping might reflect processing of the skipped word on the prior fixation or re-programming of the saccade target. It is difficult at this point to determine why some studies have reported inflated fixations and some have not. Inflated processing time prior to a skip is an important characteristic of the E-Z Reader model (Reichle et al., 1998), and further research will need to determine more precisely the relationship between skips and fixations. It may be the case that not much processing cost due to skipping is inflicted on the processing system as a result of a skip. For the moment, however, and more central to the points addressed in this chapter, we continue to believe that skipping is prima facie evidence that the meaning of a parafoveal word can sometimes be processed on the current fixation.

\section{Parafoveal Preview Benefits}

One of the most robust findings in research on eye movements and reading is that a preview of the word to the right of fixation results in shorter fixations on that word when it is fixated on the next fixation. This was first demonstrated by Rayner (1975) and has been replicated many times (see Rayner, 1998). The size of the preview benefit is typically on the order of 20-50 ms. However, exactly how much of a preview benefit the reader obtains is influenced by characteristics of the text. For example, Balota, Pollatsek, and Rayner (1985) 
found greater parafoveal preview benefit when the target word was predictable from the prior text, indicating that the extraction of parafoveal information is more efficient when aided by sentential context. Interestingly, they also found that a word is not nessarily accurately identified since nonwords that were visually similar to a target word were skipped some of the time. Furthermore, as a corollary to Balota et al.'s finding, it has also been found that when the difficulty associated with processing the fixated word is high that the extraction of parafoveal information decreases (Henderson \& Ferreira, 1990; Kennison \& Clifton, 1995; Rayner, 1986).

A number of studies have addressed the basis of preview benefit and the general conclusion is that benefit derives from abstract letter codes (McConkie \& Zola, 1979; Rayner, McConkie, \& Zola, 1980), orthographic codes in the form of the beginning letters of words (Inhoff, 1989; Rayner, Well, Pollatsek, \& Bertera, 1982), and phonological codes (Henderson, Dixon, Petersen, Twilley, \& Ferreira, 1995; Pollatsek, Lesch, Morris, \& Rayner, 1992). Interestingly, and somewhat surprisingly, research aimed at determining the extent to which semantic codes contribute to the amount of preview benefit have not found evidence to support the importance of semantic codes.

Rayner, Balota, and Pollatsek (1986) used the boundary paradigm introduced by Rayner (1975) to examine the extent to which semantic codes contributed to preview benefit. In their experiment, readers read a sentence such as "My younger brother has brilliantly composed a new song for the school play”. When subjects began reading the sentence, either song, tune, sorp, or door occupied the target location. When the reader's eye movement crossed an invisible boundary location (the letter $\mathbf{w}$ in new), a display change occurred such that the preview stimulus changed to the target word song. Among the four previews, song is identical to the target word, tune is semantically related to the target word, sorp is a nonword that is orthographically and visually similar to the target word, and door is an unrelated 
word. In a standard priming experiment (in which the prime appeared for $200 \mathrm{~ms}$ in the center of vision followed by the target word in the same location), Rayner et al. found a significant priming effect for the related word (on the order of $20 \mathrm{~ms}$ ). However, in the reading experiment (where the prime word appeared in the parafovea followed by the target word in the center of vision following an eye movement), when the same stimuli that produced a standard priming effect were used, there was no facilitation from the semantically related preview. On the other hand, the orthographically related preview did provide facilitation (see Table 2).

Insert Table 2 about here

More recently, Altarriba, Kambe, Pollatsek, and Rayner (2001) provided a stronger test of the extent to which semantic codes contribute to the amount of preview benefit. They had Spanish-English bilingual readers, who were equally fluent in each language, read sentences in which the preview was either identical to the target word (e.g. sweet-sweet), a cognate (which looked very similar to the target and meant the same thing as the target word e.g. crema-cream), a pseudo-cognate (which looked very similar to the target word, but did not mean the same thing e.g. grasa-grass), a non-cognate translation (which meant the same thing as the target word, but did not look like it e.g. dulce-sweet), or a control word (which was semantically and orthographically unrelated to the target word e.g. torre-cream). Note that the design of this study makes it possible to assess the extent to which semantic and orthographic codes contribute to preview benefit. That is, a comparison of the cognate, pseudo-cognate, and noncognate conditions provides more information than the Rayner et al. study was able to provide. Specifically, by using cognates and translations it was possible to more systematically vary the orthographic and semantic similarity between the target and preview. Table 3 shows the results of the study. Importantly, the non-cognate translation 
previews, which were semantically, but not orthographically, related to the target word, did not provide any preview benefit. The basic conclusion from the study is that orthographic codes yield preview benefit, but that semantic codes are not used in integrating information across saccades.

\section{Insert Table 3 about here}

Other experiments (Lima, 1987; Kambe, 2002) have likewise provided no evidence that morphological codes are used in integrating information across saccades for readers of English. On the other hand, some recent studies (Deutsch, Frost, Pollatsek, \& Rayner, 2000; Deutsch, Frost, Peleg, Pollatsek, \& Rayner, 2002) have demonstrated parafoveal preview benefit effects in Hebrew due to morphology. In Hebrew, morphology tends to be more important than it is in English and the experiments by Deutsch and colleagues have demonstrated that a preview of the root morpheme facilitates processing of a target word. This finding is particularly interesting since the root morpheme is distributed throughout the word and not confined to the beginning of the word (where preview benefits in English are strongest). Future research will have to determine if such effects are apparent in other languages. However as noted earlier, with respect to English, the preview benefit (or priming effect) that is obtained is due to orthographic codes, abstract letter codes, and phonological codes. But, semantic information apparently does not contribute to the effect.

\section{Parafoveal-on-Foveal Effects?}

There are two distinct types of parafoveal-on-foveal effects. Fixation durations on the foveal word $n$ might be influenced by the characteristics of word $n+1$ either when (1) word $\mathrm{n}+1$ is skipped or (2) when it is subsequently fixated. As discussed above, for the first such type of effect (word skipping) there is some suggestion that fixations on word $\mathrm{n}$ and word $n+2$ are inflated when word $n+1$ is skipped. Such effects could be explained by parallel processing of multiple words (Engbert et al., 2002), or, as serial attention shift models 
(Reichle et al., 1998) suggest, in terms of re-programming of saccades to word $n+2$. In this section we will focus on parafoveal-on-foveal effects when both word $n$ and word $n+1$ are fixated. With respect to this type of parafoveal-on-foveal effect, Kennedy $(1998,2000)$, Kennedy, Pynte, and Ducrot (2002), Murray (1998), Murray \& Rowan (1998), Inhoff, Radach, Starr, and Greenberg (2000), Inhoff, Starr, and Shindler (2000), and Underwood, Binns, and Walker (2000) have all reported results in which some characteristic of the word to the right of fixation influenced how long readers looked at the fixated word. While such effects may be valid, we believe that at the moment there are at least three reasons why it might be premature to conclude that they demonstrate parafoveal-on-foveal effects during reading. First, we suspect that there is some question about the generalizability of the results. Second, studies examining the effect of the frequency of the word to the right of fixation have typically reported null effects. Third, not all studies show parafoveal-on-foveal effects. We will now discuss each of these points.

Generalizability. In the experiments reported by Kennedy and colleagues, while subjects are engaged in tasks that admittedly bear some similarities to reading, the fact remains that they are not reading. Specifically, in Kennedy and colleagues' studies the tasks usually require subjects to look at a fixation point and then words are presented to the right of fixation. The task is to determine if the words belong to a particular semantic category (e.g., clothing) or look or mean the same. In these studies, frequently a large number of variables are simultaneously orthogonally manipulated to produce results that are quite complex (and vary slightly from study to study). These experiments have produced parafoveal-on-foveal effects related to the frequency of the word to the right of fixation (though the effect is modulated by the informativeness of word $n+1$ and the word length of word $n$ and word $n+1$ ) and orthographic properties of the letters at the beginning of the word to the right of fixation. While subjects do indeed fixate on the target words for times approximating reading fixations 
(though the mean gaze durations are usually somewhat longer than in reading), it is clearly the case that the subjects are not performing the majority of psycholinguistic processes that would normally occur during reading. To this extent, these tasks do not approximate reading. Instead, it seems to us that they are much more like a variant of a visual search task. While experiments using a visual search methodology have provided a substantial amount of data that are informative for saccade generation during the processing of visual arrays and scenes, it is not clear that they provide data relevant to the oculomotor control decisions relating to normal language processing. In support of this claim, Rayner and Fischer (1996) and Rayner and Raney (1996) demonstrated that when subjects search through text for a target word, the ubiquitous frequency effect wherein readers look longer at low frequency words than high frequency words (Inhoff \& Rayner, 1986; Rayner \& Duffy, 1986; see Rayner, 1998 for an overview) disappears. Thus, when normal language processing is not required in order to perform the task, very reliable phenomena occuring due to the linguistic characteristics of the text fail to occur. Note that although some artificial task studies of parafoveal-on-foveal effects have found frequency effects (Kennedy et al., 2002), not all have, and such tasks simply do not demand many aspects of normal language processing (such as the effects in reading that are due to predictability and to sentence structure). Thus, we suspect that there are very good reasons to question the generalizability of these results to reading.

In the experiments by Murray (1998) and Murray and Rowan (1998), once again an artificial task that at best approximates reading is used. Specifically, subjects were presented with two sentences such as "The savages smacked the child” and "The uranium smacked the child” one below the other. Subjects were required to make a decision regarding whether the sentences were physically identical or not. When they were different, the two sentences differed by one word. Importantly, psycholinguistic processing is not required in order to make such a judgment. Indeed, one could argue that the task used by Murray is also some 
variant of a visual search task, or some form of visual discrimination task. Murray’s key manipulation was that the sentences varied in the extent to which they were plausible or implausible. For example, the sentence "The uranium smacked the child" is obviously implausible because uranium is an inanimate object and therefore can't smack anything. Murray found that when readers fixated on word $n$ (uranium in the example), if word $n+1$ (smacked) resulted in an implausible reading, the fixation on word n was inflated even when word $n+1$ was subsequently fixated. This was especially true when the reader fixated near the end of word n. So, in contrast to many studies (see Garrod \& Terras, 2000; Pickering \& Traxler, 1998) in which effects of plausibility show up rather late in processing (often after the eyes have left the implausible region), Murray found effects of plausibility before the word which made the sentence implausible had been fixated. However, when we (Rayner \& Miller) attempted to replicate this result in a natural reading situation in which readers were asked to read sentences and respond to comprehension questions, no evidence for a parafoveal-on-foveal effect was found. Indeed, the plausibility manipulation had very little effect on first pass reading time and was primarily limited to second pass reading times. Perhaps the fact that the primary task in Murray's experiment was to decide if the two sentences were physically identical led subjects to employ processes that are different from those they use when they read normally.

Unlike the studies we just discussed, two studies by Inhoff et al. (2000) did involve subjects in a reading task. Inhoff, Starr et al.'s experiment is very similar to other preview studies we described above in that a display change occurred when readers moved their eyes across an invisible boundary. Sentences such as the following were used: "He approached the yellow traffic light with some caution.” When readers began reading the sentence, either the target word light was in the sentence or one of the following previews was present: LIGHT (an uppercase version preview of the target word), qvtqp (an orthographically 
illegal preview), or smoke (an unrelated preview word). When fixations on the target word following the display change were examined, the results were consistent with the results we mentioned earlier (the latter two conditions yielded longer fixation times on the word than the identical or uppercase condition). Thus, the results are consistent with orthographic/abstract letter code facilitation as the basis for the preview benefit. The other aspect of Inhoff, Starr et al.'s data which has been taken as support for parafoveal-to-foveal effects was that they also examined the fixation time on traffic as a function of the nature of the preview. While there was no effect due to the meaning of the word to the right of fixation (there was no difference between when light or smoke was the preview), the capital letter preview condition and the orthographically illegal preview condition both resulted in longer fixation times on traffic. Interestingly (see the next section), Inhoff, Starr, et al. reported a post-hoc analysis in which frequency was examined. They found no effect of the frequency of the word to the right of fixation on the current fixation time. Inhoff, Starr et al. therefore found no evidence that semantic processing of a word influences fixation durations on the previous word. However, they did find some evidence that unusual orthography at the beginning of word $n+1$ resulted in longer fixations on word $n$. Underwood et al. (2000) also found that unusual orthography at the word beginning of word $n+1$ can increase fixation durations on word n.

Inhoff, Radach et al. did find some evidence for semantic processing of the word to the right of fixation. They used sentences such as "Did you see the picture of her mother's mother at the meeting?” Reading times on mother's were compared when the following word was mother (identical), father (associated), or garden (unassociated). There were no text changes in this experiment. Inhoff, Radach et al. found that first fixation and gaze durations were shorter if the following word was either identical or associated to the fixated 
word, compared to when the following word was unassociated. Nevertheless, the fact that Inhoff, Starr et al. and the studies discussed below have not found evidence for semantic parafoveal-on-foveal effects indicates that the effects are not robust.

Furthermore, it is also interesting to note that the direction of parafoveal-on-foveal effects is not consistent. Sometimes the effect from the word to the right of fixation manifests itself in shorter fixations and other times it manifests itself in a longer fixation. For example, in a sentence reading experiment Underwood et al. (2000) found that fixations on the foveal word were longer when word $n+1$ had an informative initial trigram. In contrast, in artificial task experiments by Kennedy $(1998,2000)$ fixations on the foveal word were shorter when word $n+1$ had an informative initial trigram. While it might be possible to account for these differences (see Kennedy et al., 2002), one might hope for more consistency.

While the studies by Kennedy, Murray, and Inhoff et al. have been taken by some as evidence for parafoveal-on-foveal effects, it is important to note that there has been no consistent evidence that the meaning of the word to the right of fixation influences the fixation time on the current fixation. Indeed, Inhoff. Starr et al.’s primary finding (see also Underwood et al.) was that orthographic distinctiveness (either in the form of an unfamiliar uppercase string or an orthographically illegal string) of the word to the right of fixation can have some effect on the current fixation time. Such an effect has also been obtained by Kennedy and we shall see some further evidence of this effect below. But, the generalizability issue that we have raised (concerning the extent to which non-reading tasks generalize to reading) together with Inhoff, Starr et al.'s results are consistent with the idea that the meaning of the word to the right of fixation is not influencing the current fixation time.

Lack of Parafoveal-on-Foveal Frequency Effects. As we noted above, there are very robust frequency effects for fixated words: low frequency words are reliably fixated 
longer than high frequency words (see Rayner, 1998 for a review). Some studies using artificial tasks have found effects of the frequency of word $n+1$ on reading times on word $n$ (Kennedy, 2000; Kennedy, Pynte, \& Ducrot, 2002) and others have not (Schroyens, Vitu, Brysbaert, \& d’Ydewalle, 1999). However, four different reading studies (Carpenter \& Just, 1983; Henderson \& Ferreira, 1993; Inhoff, Starr et al., 2000; Rayner et al., 1998) have examined the effect of the frequency of the word to the right of fixation on the fixation time on the currently fixated word, and all of these studies have reported null effects. Namely, they found that the frequency of the word to the right of fixation did not influence fixation time on the fixated word. Such findings are clearly at odds with the view that semantic characteristics of the parafoveal word influence the fixation time on the currently fixated word. In order for the semantic characteristics of the parafoveal word to become available and influence foveal processing, readers must necessarily have identified the parafoveal word. Probably the most robust finding associated with word identification is the frequency effect. Consequently, we might therefore reasonably anticipate that the frequency of the parafoveal word would significantly modulate any semantic parafoveal-on-foveal effect that might occur. That is to say, if semantic parafoveal on foveal effects did occur, then one would expect longer fixations on the currently fixated word when the parafoveal word was low frequency and shorter fixations when the parafoveal word was high frequency. Rather, as we have noted, the fixation time is driven by the frequency of the currently fixated word, not the parafoveal word. It is also interesting to note that the effects reported Kennedy et al. (2002) are in the opposite direction with longer fixations on foveal words when $n+1$ was high frequency (though they do provide arguments for why the direction of the effect might be different).

Lack of Parafoveal-on-Foveal Effects. Although the topic of parafoveal-on-foveal effects has recently attracted a fair amount of attention, the issue was actually anticipated in 
the early Rayner (1975) study. Although this study is typically discussed in the context of preview benefit, it is the case that possible parafoveal-on-foveal effects were examined. Specifically, Rayner examined the duration of the last fixation prior to crossing the boundary and fixating on the target word. Furthermore, the duration of the last fixation was examined as a function of the launch site of the saccade that crossed the boundary. Figure 1 shows these data.

\section{Insert Figure 1 about here}

In Rayner's study, reader's read sentences such as “The soldiers guarded the palace throughout the day" with palace as the target word following the display change. The preview was either palace, a word that was orthographically similar to the target word (police), or nonwords that varied in their orthographic similarity to the target word (pcluce, pyctce, or qcluec). As is clear in Figure 1, there were no differences between any of the conditions when the saccade was launched from 4 or more character spaces from the beginning of the target word. When the eyes were 1 to 3 character spaces from the beginning of the target word, launch site fixations were longer for the nonword conditions than the two word conditions. Apparently then, the orthographic irregularity of the beginning of the nonwords was registered by the processing system resulting in a longer launch site fixation. Such a pattern was also observed in some of the studies we reviewed above. It should also be noted that in the original Rayner (1975) study, the boundary location was sometimes set partway into the target word. Thus, it was quite possible for readers to occasionally fixate on the preview word before it changed to the target word. In this case, the three nonword conditions resulted in fixations on the target word that averaged over $400 \mathrm{~ms}$ (in comparison to $218 \mathrm{~ms}$ for the two word conditions).

Three other studies that examined the duration of the fixation prior to fixating on a target word likewise revealed little difference as a function of the semantic information in the 
target word location. First, in the Rayner et al. (1986) study discussed earlier, examination of the last fixation duration and the gaze duration on the word fixated prior to crossing the boundary location and triggering the display change revealed no effects of the preview word (see Table 4). Second, examination of the last fixation prior to fixating on the target word in the Altarriba et al. (2001) study discussed earlier likewise revealed no effects of the preview word. Third, a recent study by White and Liversedge (2002) also found no effects on the launch site fixation.

\section{Insert Tables 4 and 5about here}

White and Liversedge had readers read sentences in which a misspelling occurred at the beginning of a target word. A correctly spelled condition (e.g., agricultural) was compared to four misspelled conditions that created word beginnings with different degrees of orthographic irregularity. These ranged from initial trigrams that were pronounceable and high frequency (e.g., acricultural) to initial trigrams that never occur at the word beginning and which were unprounceable (e.g. ngricultural). There was no display change manipulation in this experiment so readers could directly fixate the misspelled word. Importantly, White and Liversedge did find that first fixation landing positions on the critical word were significantly nearer the word beginning if the word was misspelled compared to the correctly spelled condition. Therefore the misspellings were processed before the critical words were fixated. Consequently, if there are strong parafoveal-on-foveal effects there should be differences in the fixation durations prior to fixating the critical word. However, there were no effects of spelling on prior fixation durations (for word n-1), even for fixations very close to the left of the critical word. Figure 2 shows the fixation durations for each area of prior fixation and it is apparent that there is no consistent pattern in terms of the fixation duration as a function of the target condition. We also examined whether the last fixation was a refixation or a single fixation and found no difference in the data pattern between these two 
types of fixations. Likewise, there was no effect on refixation probability on word n-1 as a function of the target condition. Therefore White and Liversedge's results provide no support for parafoveal-on-foveal effects.

Insert Figure 2 about here

Finally, Kambe (2002) recently used the boundary paradigm to investigate the possibility of morphology contributing to preview benefit. She had readers read sentences in which target words were prefixed words (such as preview). Readers received either the identical word to the target word as a preview (preview), or just the prefix with the other letters replaced by similar letters (preurcv), or an unrelated string of letters (qncurcv). She, like Lima (1987), found no evidence for morphological priming effects ${ }^{1}$. However, we examined the launch site fixation duration in her study. Figure 3 shows these data. Once again, consistent with the Rayner (1975) study, we see that when the launch site was more than 4 letters from the beginning of the target word there was no difference between conditions. However, the orthographically illegal string at the beginning of the unrelated preview condition resulted in longer launch fixations when the eyes were within 3 characters of the beginning of the target word.

Insert Figure 3 about here

Taken together, the results of the studies we have discussed in this section provide rather clear evidence against parafoveal-on-foveal processing in terms of semantic effects. Some studies (Inhoff, Starr et al., 2000; Kambe, 2002; Rayner, 1975) show effects due to unusual orthographic patterns at the beginning of a target region influencing the duration of the current fixation when the eyes are within 3 letter spaces of that region. However, other studies (White \& Liversedge, 2002) do not even show an effect of unusual orthography at the beginning of a subsequent target string influencing the current fixation. 
In this chapter, we have reviewed research dealing with semantic processing in parafoveal vision during reading. We have made five arguments based on the data reviewed. First, we argued that reading on the basis of parafoveal information is quite difficult (Rayner \& Bertera, 1979; Rayner et al., 1981). Second, we argued that word skipping is evidence that readers can sometimes obtain the meaning of a word to the right of fixation; our view is that when a word is identified to the right of fixation, it will typically be skipped. Third, we argued against the notion of semantic preprocessing wherein the eyes move further into words that have informative endings (Hyönä, 1995; Rayner \& Morris, 1992). Fourth, we reviewed evidence that indicates that semantic codes are not the source of preview benefit effects in reading (Altarriba et al., 2001; Rayner et al., 1986); the source of the preview benefit appears to be some type of abstract letter code and/or phonological code. Finally, we have suggested that it would be premature at this point to assume that there are semantic parafoveal-on-foveal effects in reading. In this regard, we suggested that there may well be problems with the generalizability of some of the studies purporting to show such effects and have further suggested that in the context of reading per se, while there may be parafovealon-foveal effects due to unusual orthography at the beginning of the word to the right of fixation, there is not much convincing evidence for the effects being due to the meaning of the word to the right of fixation. Indeed, a number of studies have demonstrated that the frequency of the word to the right of fixation has no effect on the duration of the current fixation; however, the duration of the current fixation is strongly influenced by the frequency of the currently fixated word.

As we noted at the outset of this chapter, the main reason that parafoveal-on-foveal effects have attracted so much attention is because it has been assumed that such effects would be damaging to serial attention shift models like the E-Z Reader model. While it is the case that if the meaning of the word to the right of fixation exerted a strong effect on the 
current fixation duration it would be problematic for the model, it is also the case that parafoveal-on-foveal effects due to orthographic irregularity at the beginning of the parafoveal word are not necessarily a problem. Indeed, the most recent version of the model (Pollatsek, Reichle, \& Rayner, this volume; Reichle, Rayner, \& Pollatsek, 2002) has incorporated a mechanism that can accommodate such an effect. In the earliest versions of the model (Reichle et al., 1998; Reichle, Rayner, \& Pollatsek, 1999), the eye movement program to move the eyes to the next unidentified word and the associated shift of attention to that word followed from the completion of a familiarity check and completion of lexical access, respectively. In the more recent version of the model, a pre-attention stage of processing has been incorporated. Thus, information about word length and letter information could be extracted prior to shifting attention. This contrasts with the earlier versions of the model in which no meaningful extraction of letter information occurred before an attention shift. The current version of the model was not necessarily constructed to account for orthographic irregularity effects, but it is not inconsistent with the model that unusual combinations of letters could be noticed by this pre-attentive processing and influence eye movement behavior. Thus, parafoveal-on-foveal effects due to unusual orthography at the beginning of a word would be independent of serial attention shifts associated with lexical access.

It should also be noted that even if it were the case that effects like those reported by Murray (1998) and Inhoff, Radach, et al. (2000) proved to be reliable, the E-Z reader model would be able to partially account for the data. Specifically, if the effect was driven by fixations on the end of the word n, it could conceivably be the case that some of the time readers will undershoot their saccade and be intending to fixate (and attend to) word $n+1$ while they're fixating near the end of word n. Such an undershoot explanation could conceivably account for effects such as those reported by Murray and Inhoff, Radach et al. 
In conclusion, then, we accept that a word to the right of a fixated word can be identified and that when this happens the word is subsequently skipped. This usually happens for short words when the reader fixates very close to them. However, we feel that it would be very premature at this point to accept that there is any strong evidence obtained from a natural reading task to suggest that semantic information is obtained from the parafovea, except in those cases when the parafoveal word is subsequently skipped. It does appear that there is some evidence suggesting that orthographic irregularities at the beginning of the parafoveal word can influence the duration of the next fixation when the eyes are close (within three character spaces) to the beginning of that word. However, this finding is not problematic for the E-Z Reader model. Furthermore, we have argued that there is no convincing evidence for semantic preprocessing in terms of the eyes being drawn to the informative end of a parafoveal word. Finally, the basis for the robust parafoveal preview benefit obtained in numerous studies is not any type of semantic code, but rather abstract letter/phonological codes related primarily to the beginning letters of parafoveal words ${ }^{2}$. But, once again, as we noted at the outset of this concluding paragraph, it would be premature to argue that the meaning of the word to the right of fixation has any influence on the duration of the current fixation when that word is not skipped. 


\section{References}

Altarriba, J., Kambe, G., Pollatsek, A., \& Rayner, K. (2001). Semantic codes are not used in integrating information across eye fixations in reading: Evidence from fluent Spanish English bilinguals. Perception \& Psychophysics, 63, 875-890.

Balota, D.A., Pollatsek, A., \& Rayner, K. (1985). The interaction of contextual constraints and parafoveal visual information in reading. Cognitive Psychology, 17, 364390.

Blanchard, H.E., Pollatsek, A., \& Rayner, K. (1989). The acquisition of parafoveal word information in reading. Perception \& Psychophysics, 46, 85-94.

Brysbaert, M., \& Vitu, F. (1998). Word skipping: Implications for theories of eye movement control in reading. In G. Underwood (Ed.), Eye Guidance in Reading and Scene Perception (pp.125-148). Oxford, England: Elsevier.

Carpenter, P.A., \& Just, M.A. (1983). What your eyes do while your mind is reading. In K. Rayner (Ed.), Eye movements in reading: Perceptual and language processes (pp. 275-307. New York: Academic Press.

Deutsch, A., Frost, R., Peleg, S., Pollatsek, A., \& Rayner, K. (2002). Early morphological effects in reading: Evidence from parafoveal preview benefit in Hebrew. Psychonomic Bulletin \& Review, in press.

Deutsch, A., Frost, R., Pollatsek, A., \& Rayner, K. (2000). Early morphological effects in word recognition in Hebrew: Evidence from parafoveal preview benefit. Language and Cognitive Processes, 15, 487-506.

Ehrlich, S. F., \& Rayner, K. (1981). Contextual effects on word perception and eye movements during reading. Journal of Verbal Learning and Verbal Behavior,20, 641-655.

Engbert, R., Longtin,A., \& Kliegl, R. (2002). A dynamical model of saccade 
generation in reading based on spatially distributed lexical processing. Vision Research, 42, 621-636.

Everatt, J., \& Underwood, G. (1992). Parafoveal guidance and priming effects during reading: A special case of the mind being ahead of the eyes. Consciousness and Cognition, 1, 186-197.

Garrod, S., \& Terras, M. (2000). The contributions of lexical and situational knowledge to resolving discourse roles: Bonding and resolution. Journal of Memory and Language, 42, 526-544.

Gautier, V., O’Regan, J.K., \& LaGargasson, J.F. (2000). ‘The skipping’ revisited in French: programming saccades to skip the article ‘les’. Vision Research, 40, 2517-2531.

Henderson, J.M., Dixon, P., Peterson, A., Twilley, L.C., \& Ferreira, F. (1995). Evidence for the use of phonological representations during transaccadic word recognition. Journal of Experimental Psychology: Human Perception and Performance, 21, 82-97.

Henderson, J.M., \& Ferreira, F. (1993). Eye movement control during reading: Fixation measures reflect foveal but not parafoveal processing difficulty. Canadian Journal of Experimental Psychology, 47, 201-221.

Henderson, J.M., \& Ferreira, F. (1990). Effects of foveal processing difficulty on the perceptual span in reading: Implications for attention and eye movement control. Journal of Experimental Psychology: Learning, Memory and Cognition, 16, 417-429.

Hyönä, J. (1993). Effects of thematic and lexical priming on readers’ eye movements. Scandinavian Journal of Psychology, 34, 293-304.

Hyönä, J. (1995). Do irregular letter combinations attract readers’ attention? Evidence from fixation locations in words. Journal of Experimental Psychology: Human Perception and Performance, 21, 68-81. 
Hyönä, J., Niemi, P., \& Underwood, G. (1989). Reading long words embedded in sentences: Informativeness of word halves affects eye movements. Journal of Experimental Psychology: Human Perception and Performance, 15, 142-152.

Inhoff, A.W. (1989). Parafoveal processing of words and saccade computation during eye fixations in reading. Journal of Experimental Psychology: Human Perception and Performance, 15, 544-555.

Inhoff, A. W., Radach, R., Starr, M., \& Greenberg, S. (2000) Allocation of visuospatial attention and saccade programming during reading. In A. Kennedy, R. Radach, D. Heller, \& J. Pynte (Eds.), Reading as a perceptual process (pp. 221-246). Oxford, UK: Elsevier.

Inhoff, A.W., \& Rayner, K. (1986). Parafoveal word processing during eye fixations in reading: Effects of word frequency. Perception \& Psychophysics, 40, 431-439.

Inhoff, A.W., Starr, M., \& Shindler, K.L. (2000). Is the processing of words during eye fixations in reading strictly serial? Perception \& Psychophysics, 62, 1474-1484.

Jacobs, A.M. (1987). On the role of blank spaces for eye-movement control in visual search. Perception \& Psychophysics. 41, 473-479.

Kambe, G. (2002) Parafoveal processing of morphologically complex (prefixed) words during eye fixations in reading: Evidence against morphological decomposition in reading. Submitted for publication.

Kennedy, A. (1998). The influence of parafoveal words on foveal inspection time: Evidence for a preprocessing trade off. In G. Underwood (Ed.), Eye guidance in reading and scene perception (pp.149-180). Oxford, England: Elsevier.

Kennedy, A. (2000). Parafoveal processing in word recognition. Quarterly Journal of Experimental Psychology, 53A, 429-455. 
Kennedy, A., Pynte, J., \& Ducrot, S. (2002). Parafoveal-on-foveal interactions in word recognition. Quarterly Journal of Experimental Psychology. In press.

Kennison, S.M., \& Clifton, C. (1995). Determinants of parafoveal preview benefit in high and low working memory capacity readers: Implications for eye movement control. Journal of Experimental Psychology: Learning Memory and Cognition, 21, 68-81.

Kennison, S.M., \& Gordon, P.C. (1998). Comprehending referential expressions during reading: Evidence from eye tracking. Discourse Processes, 24, 229-252.

Lima, S.D. (1987). Morphological analysis in sentence reading. Journal of Memory and Language, 26, 84-99.

Liversedge, S.P., \& Findlay, J.M. (2000). Saccadic eye movements and cognition. Trends in Cognitive Sciences, 4, 6-14.

McConkie, G.W., \& Rayner, K. (1975). The span of the effective stimulus during a fixation in reading. Perception \& Psychophysics, 17, 578-586.

McConkie, G.W., \& Zola, D. (1979). Is visual information integrated across successive fixations in reading. Perception \& Psychophysics, 25, 221-224.

Morrison, R.E., \& Rayner, K. (1981). Saccade size in reading depends upon character spaces and not visual angle. Perception \& Psychophysics, 30, 395-396.

Murray, W.S. (1998). Parafoveal pragmatics. In G. Underwood (Ed.), Eye guidance in reading and scene perception (pp. 181-200). Oxford, England: Elsevier.

Murray, W.S., \& Rowan, M. (1998). Early, mandatory, pragmatic processing. Journal of Psycholinguistic Research, 27, 1-22.

O’Regan, K. (1979). Saccade size control in reading: Evidence for the linguistic control hypothesis. Perception \& Psychophysics, 25, 501-509.

O’Regan, K. (1980). The control of saccade size and fixation duration in reading: The 
limits of linguistic control. Perception \& Psychophysics, 28, 112-117.

O’Regan, K. (1983). Elementary perceptual and eye movement control processes in reading. In K. Rayner (Ed.), Eye movements in reading: Perceptual and language processes (pp. 121-140). New York: Academic Press.

O’Regan, J.K., Lévy-Schoen, A., \& Jacobs, A.M. (1983). The effect of visibility on eye movement parameters in reading. Perception \& Psychophysics, 34, 457-464.

Pickering, M.J., \& Traxler, M.J. (1998). Plausibility and recovery from garden paths: An eye-tracking study. Journal of Experimental Psychology: Learning, Memory, and Cognition, 24, 940-961.

Pollatsek, A., Lesch, M., Morris, R.K., \& Rayner, K. (1992). Phonological codes are used in integrating information across saccades in word identification and reading. Journal of Experimental Psychology: Human Perception and Performance, 18, 148-162.

Pollatsek, A., \& Rayner, K. (1982). Eye movement control in reading: the role of word boundaries. Journal of Experimental Psychology: Human Perception and Performance, 8, 817-833.

Pollatsek, A., Rayner, K., \& Balota, D.A. (1986). Inferences about eye movement control from the perceptual span in reading. Perception \& Psychophysics, 40, 123-130.

Pollatsek, A., Reichle, E.D., \& Rayner, K. (2002). Modeling eye movements in reading: Extending the E-Z Reader model. This volume.

Radach, R., \& Heller, D. (2000). Relations between spatial and temporal aspects of eye movement control. In A. Kennedy, R. Radach, D. Heller, \& J. Pynte (Eds.), Reading as a perceptual process (pp. 165-191). Oxford, UK: Elsevier.

Radach, R., Krummenacher, J, Heller, D., \& Hofmeister, J. (1995). Individual eye movement patterns in word recognition: Perceptual and linguistic factors. In J.M. Findlay, R. 
Walker, \& R.W. Kentridge (Eds.), Eye Movement Research: Mechanisms, processes and applications (pp.421-432). Amsterdam: North Holland.

Rayner, K. (1975). The perceptual span and peripheral cues in reading. Cognitive Psychology, 7, 65-81

Rayner, K. (1978). Eye movements in reading and information processing. Psychological Bulletin, 85, 618-660.

Rayner, K. (1979). Eye guidance in reading: fixation locations within words. Perception, 8, 21-30.

Rayner, K. (1986). Eye movements and the perceptual span in beginning and skilled readers. Journal of Experimental Child Psychology, 41, 211-236.

Rayner, K. (1998). Eye movements in reading and information processing: 20 years of research. Psychological Bulletin, 124, 372-422.

Rayner, K., Ashby, J., Pollatsek, A., \& Reichle, E.D. (2002). The effects of frequency and predictability on eye fixations in reading: Implications for the E-Z Reader model. In prep.

Rayner, K., \& Bertera, J.H. (1979). Reading without a fovea. Science, 206, 468-469.

Rayner, K., Balota, D.A., \& Pollatsek, A. (1986). Against parafoveal semantic preprocessing during eye fixations in reading. Canadian Journal of Psychology,40,473-483.

Rayner, K., \& Duffy, S.A. (1986). Lexical complexity and fixation times in reading: Effects of word frequency, verb complexity and lexical ambiguity. Memory And Cognition, 14, 191-201.

Rayner, K., \& Fischer, M.H. (1996). Mindless reading revisited: Eye movements during reading and scanning are different. Perception \& Psychophysics, 58, 734-747.

Rayner, K., Fischer, M.H., \& Pollatsek, A. (1998). Unspaced text interferes with both 
word identification and eye movement control. Vision Research, 38, 1129-1144.

Rayner, K., Inhoff, A.W., Morrison, R.E., Slowiaczek, M.L., \& Bertera, J.H. (1981). Masking of foveal and parafoveal vision during eye fixations in reading. Journal of Experimental Psychology: Human Perception and Performance, 7, 167-179.

Rayner, K., \& McConkie, G.W. (1976). What guides a reader's eye movements? Vision Research, 16, 829-837.

Rayner, K., McConkie, G. W., \& Zola, D. (1980). Integrating information across eye movements. Cognitive Psychology, 12, 206-226.

Rayner, K., \& Morris, R.K. (1992). Eye movement control in reading: Evidence against semantic preprocessing. Journal of Experimental Psychology: Human Perception and Performance, 18, 163-172.

Rayner, K., \& Morrison, R.M. (1981). Eye movements and identifying words in parafoveal vision. Bulletin of the Psychonomic Society, 17, 135-138.

Rayner, K., \& Raney, G.E. (1996). Eye movement control in visual search: Effects of word frequency. Psychonomic Bulletin \& Review, 3, 238-244.

Rayner, K., \& Well, A.D. (1996). Effects of contextual constraint on eye movements in reading: A further examination. Psychonomic Bulletin and Review, 3, 504-509.

Rayner, K., Well, A.D., Pollatsek, A., \& Bertera, J.H.(1982).The availability of useful information to the right of fixation in reading. Perception \& Psychophysics, 31, 537-550.

Rayner, K., Well, A.D., \& Pollatsek, A. (1980). Asymmetry of the effective visual field in reading. Perception \& Psychophysics, 27, 537-544.

Rayner, K., Sereno, S.C., \& Raney, G.E. (1996). Eye movement control in reading: A comparison of two types of models. Journal of Experimental Psychology: Human Perception and Performance, 22, 1188-1200. 
Rayner, K., Slowiaczek, M.L., Clifton, C., \& Bertera, J.H. (1983). Latency of sequential eye movements: Implications for reading. Journal of Experimental Psychology: Human Perception and Performance, 9, 912-922.

Reichle, E. D., Pollatsek, A., Fisher, D. L., \& Rayner, K. (1998). Toward a model of eye movement control in reading. Psychological Review, 105, 125-157.

Reichle, E.D., Rayner, K., \& Pollatsek, A. (1999). Eye movement control in reading: Accounting for initial fixation locations and refixations within the E-Z Reader model. Vision Research, 39, 4403-4411.

Reichle, E.D., Rayner, K., \& Pollatsek, A. (2002) The E-Z Reader Model of Eye Movement Control in Reading: Comparisons to Other Models. Brain and Behavioral Sciences, under revision.

Schroyens, W., Vitu, F., Brysbaert, M., \& d’Ydewalle, G. (1999). Eye movement control during reading: Foveal load and parafoveal processing. Quarterly Journal of Experimental Psychology, 52A, 1021-1046.

Starr, M.S., \& Rayner, K. (2001). Eye movements during reading: Some current controversies. Trends in Cognitive Sciences, 5, 156-163.

Underwood, G. (1985). Eye movements during the comprehension of written language. In A.W. Ellis (Vol. Ed.), Progress in the psychology of language (Vol. 2, pp. 4571). London: Erlbaum.

Underwood, G., Binns, A., \& Walker, S. (2000). Attentional demands on the processing of neighbouring words. In A. Kennedy, R. Radach, D. Heller, \& J. Pynte (Eds.), Reading as a perceptual process (pp. 247-268). Oxford, UK: Elsevier.

Underwood, G., Bloomfield, R., \& Clews, S. (1988). Information influences the pattern of eye fixations during sentence comprehension. Perception, 17, 267-278. 
Underwood, G., Clews, S., \& Everatt, J. (1990). How do readers know where to look next? Local information distributions influence eye fixations. Quarterly Journal of Experimental Psychology. 42A, 39-65.

Underwood, G., Clews, S., \& Wilkinson, H. (1989). Eye fixations are influenced by the distribution of information within words. Acta Psychologica, 72, 263-280.

White, S.J., \& Liversedge, S.P. (2002). Orthographic Regularity Influences the Eyes’ Landing Positions in the Reading of English Sentences. Under revision. 


\section{Footnotes}

1. Kambe (2002) also had a stem preview condition (qscview) in her experiment which is not discussed here. In another experiment, she made the prefix and stem previews visually distinct by replaced letters with X's (preXXXX, XXXview). For more detail, see Kambe (2002).

2. As we noted earlier, in Hebrew there is evidence that morphological codes obtained from parafoveal words result in preview benefit (see Deutsch et al., 2002).

\section{Acknowledgments}

Preparation of this chapter was supported by Grant HD26765. It was written while the first author was the recipient of a Leverhulme Professorship at the University of Durham. We thank Raymond Bertram, Jukka Hyönä, Alan Kennedy, Alexander Pollatsek, and Erik Reichle for their helpful comments on an earlier draft of this chapter. 
Table 1: Example Sentences and Reading Time Measures on the Target Word (shown in bold) from Rayner and Well (1996).

High Pred: He mailed a letter without a stamp so it didn’t arrive.

Medium Pred: Some of the ashes dropped on the carpet to her dismay.

Low Pred: They were startled by the sudden voice from the next room.

$\begin{array}{lccc}\text { Constraint } & \text { FFD } & \text { GAZE } & \text { FP } \\ \text { High } & 239 & 261 & .78 \\ \text { Medium } & 240 & 261 & .88 \\ \text { Low } & 250 & 281 & .90\end{array}$

Note: FFD = first fixation duration (in ms), GAZE = gaze duration (in ms), and FP = Fixation probability. 
Table 2: Reading Time Measures on the Target Word as a Function of Preview from Rayner, Balota, and Pollatsek (1986).

$\begin{array}{lll}\text { Preview } & \text { FFD } & \text { GAZE } \\ \text { Identical (song-song) } & 214 & 246 \\ \text { Semantically Related (tune-song) } & 230 & 286 \\ \text { Unrelated (door-song) } & 234 & 290 \\ \text { Visually Similar Nonword (sorp-song) } & 215 & 251 \\ \text { Note: FFD = first fixation duration (in ms), GAZE = gaze duration (in ms) }\end{array}$


Table 3: Example Stimuli and Reading Time Measures on the Target as a Function of Preview from Altarriba, Kambe, Pollatsek, and Rayner (2001).

$\begin{array}{lllll}\text { Condition } & \text { Preview } & \text { Target } & \text { FFD } & \text { GAZE } \\ \text { Identical } & \text { Sweet } & \text { Sweet } & 267 & 342 \\ \text { Cognate } & \text { Crema } & \text { Cream } & 270 & 344 \\ \text { Pseudo-cognate } & \text { Grasa } & \text { Grass } & 273 & 346 \\ \text { Non-cognate } & \text { Dulce } & \text { Sweet } & 287 & 367 \\ \text { Control } & \text { Torre } & \text { Cream } & 290 & 371\end{array}$

Note: FFD = first fixation duration (in ms), GAZE = gaze duration (in ms). The reading time measures show the combined results for Spanish and English targets. 
Table 4: Reading Time Measures on the Word Prior to the Target as a Function of Preview from Rayner, Balota, and Pollatsek (1986).

$\begin{array}{llc}\text { Preview } & \text { Fixation n-1 } & \text { GAZE } \\ \text { Identical (song-song) } & 228 & 251 \\ \text { Semantically Related (tune-song) } & 228 & 250 \\ \text { Unrelated (door-song) } & 222 & 251 \\ \text { Visually Similar Nonword (sorp-song) } & 219 & 248\end{array}$

Note: Fixation n-1 = duration of fixation prior to fixating the target (in ms), GAZE = gaze duration (in ms). 
Table 5: Last Fixation Duration Prior to Fixating on the Target Word as a Function of Preview from Altarriba, Kambe, Pollatsek, and Rayner (2001).

$\begin{array}{lc}\text { Preview } & \text { Fixation n-1 } \\ \text { Identical (sweet-sweet) } & 265 \\ \text { Cognate (crema-cream) } & 266 \\ \text { Pseudo-cognate (grasa-grass) } & 270 \\ \text { Non-cognate (dulce-sweet) } & 269 \\ \text { Control (torre-cream) } & 268\end{array}$

Note: Fixation n-1 = duration of fixation prior to fixating the target (in ms). The results for Spanish and English targets have been combined. 


\section{Figure captions}

Figure 1: Mean fixation durations prior to fixating the critical word for each condition and for each area of prior fixation.

Figure 2: Mean fixation durations prior to fixating the critical word for each condition and for each area of prior fixation.

Figure 3: Mean fixation durations prior to fixating the critical word for each condition and for each area of prior fixation. 
Figure 1.

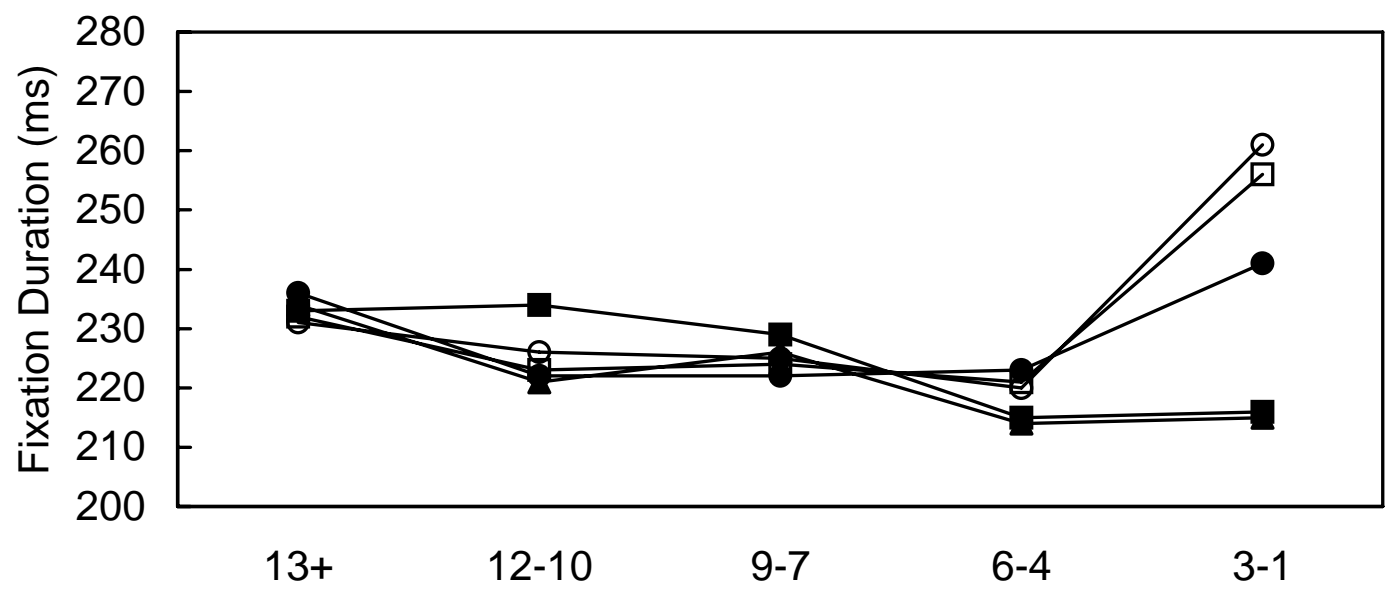

Area of Prior Fixation (No. Characters to the Left of the Critical Word)

$\neg$ palace $\rightarrow$ police $\multimap$ pcluce $\square$ pyctce $\bullet$ qcluec 
Figure 2.

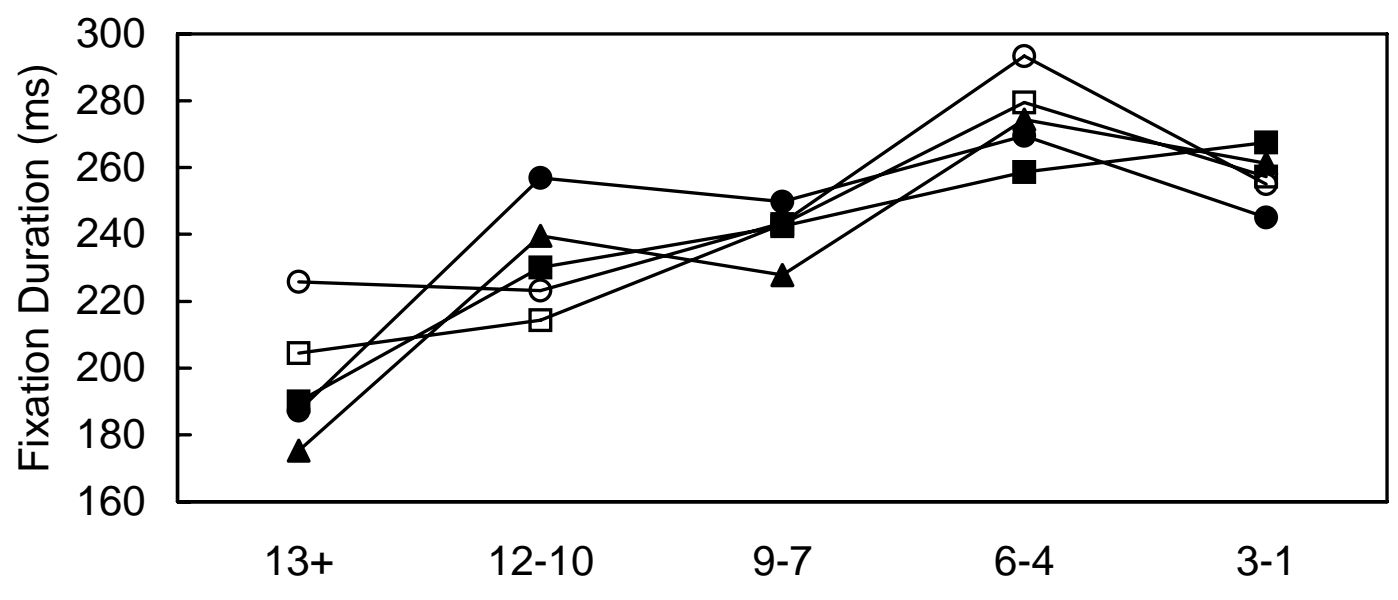

Area of Prior Fixation (No. Characters to the Left of the Critical Word)

$\rightarrow$-agricultural $\rightarrow-$ acricultural $\rightarrow$-aoricultural

$\square$ akricultural - ngricultural 
Figure 3.



